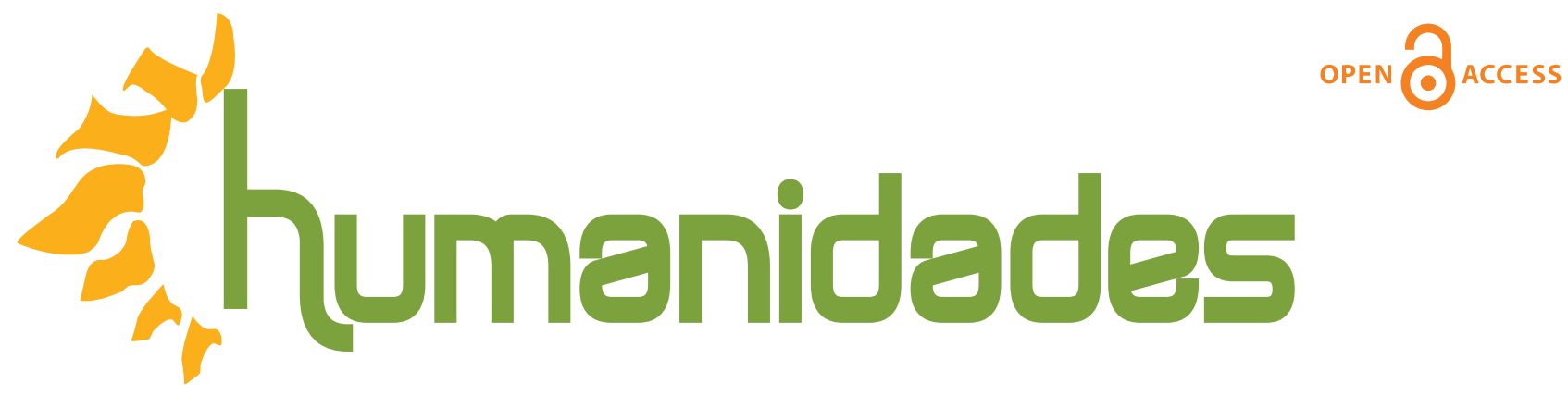

Revista de la Escuela de Estudios Generales, Universidad de Costa Rica

Julio-diciembre, 2019 •Volumen 9, número 2 • EISSN 2215-3934 • pp. 1-21

Recibido: 1-Febrero-2019 Aceptado: 2-Abril-2019

\title{
Baudrillard. Filosofía de la seducción
}

DOI: https://doi.org/10.15517/h.v9i2.37516

\section{Leopoldo Tillería Aqueveque}

Doctor en Filosofía

Universidad Tecnológica de Chile (INACAP), Chile

Correo electrónico: leopoldo.tilleria@inacapmail.cl

Todos los derechos reservados. Universidad de Costa Rica. Esta revista se encuentra licencida con Creative Commons. Reconocimiento-NoComercial-SinObraDerivada 3.0 Costa Rica. Correo electrónico: humanidades@ucr.ac.cr/ Sitioweb: http: //revistas.ucr.ac.cr/index.php/humanidades 


\title{
Baudrillard. Filosofía de la seducción
}

\section{Resumen}

El artículo aborda el problemático concepto de seducción en la obra del sociólogo y Palabras clave: filósofo francés Jean Baudrillard, alojado especialmente en su libro De la seducción (1979). Se propone una naturaleza ontológica aun cuando no metafísica para la seducción baudrillardiana, en la que el ser no tiene cabida sino como puro dominio simbólico de las formas. El trabajo también se fundamenta en la crítica del filósofo chileno Cristóbal Holzapfel, para quien la seducción absorbe el sentido de las cosas. Se sostiene que la seducción no es de naturaleza sexual, ni amorosa, porno o digital. Tampoco es flirteo, affaire o una estrategia romántica, lisa y llanamente porque el seducir opera haciendo reversible el erotismo. Al final, se observan varias estéticas de la seducción: la seducción como fantasma, ilusión, muerte y como juego, modos extraños de una seducción esencialmente heterodoxa.

\section{Baudrillard. Philosophy of Seduction}

\begin{abstract}
The article discusses the problematic concept of seduction in the work of the sociologist and French philosopher Jean Baudrillard, lodged particularly in his book Seduction (1979). Proposes a nature of ontological even if not metaphysical for baudrillardian seduction, in which the self has no place but as pure symbolic domain of forms. The work is also based on the criticism of the Chilean philosopher Cristóbal Holzapfel, for whom the seduction absorbed the sense of things. Held that seduction is not sexual, love, pornographic, or digital in nature. Nor is flirting, affair, or a romantic approach, simply because the seduce operates by reversible eroticism. In the end, there are several aesthetics of seduction: the seduction as ghost, illusion, as death and play strange modes of an essentially heterodox seduction.
\end{abstract}

Keywords: aesthetics, philosophy, play, production 
El mejor truco realizado por el Diablo fue convencer al mundo de que no existia, y asi: (buff)... desaparece...

Roger "Verbal" Kint (Kevin Spacey, The Usual

Suspects, 1995)

\section{Introducción}

En De la seducción (1979), Jean Baudrillard completa su asistemática teoría de la posmodernidad (uno de cuyos fundamentos es la noción de simulacro) presentando el desconcertante concepto de seducción, el cual parece formar parte, así como el propio Baudrillard, de un pensamiento tan extrasociológico como extrafilosófico. De ahí que suscribamos, en cierto sentido, la opinión de Francescutti (2001) cuando señala que "Baudrillard fecundó a la sociología, la antropología, la filosofía, con la creatividad ilimitada de la ciencia ficción” (p. 26). El desafío es, entonces, acoplarse al código "Baudrillard".

Baudrillard nos propone un modo de interpretación de la sociedad posmoderna y al mismo tiempo una nueva ontología en la era de la simulación. Su pensamiento es la expresión post y pop-filosófica de nuestros tiempos: disolución del principio de realidad y caída en el principio de simulación. Su discutido posestructuralismo (por no decir el pesimismo apocalíptico o el escepticismo cínico que algunos han querido ver) se observa particularmente en su declaración de la imposibilidad de la representación, es decir, del intercambio entre pensamiento y realidad, entre sujeto y objeto. El mundo real deja de existir y da paso a la metafísica de la simulación: aquella estructura de hacer desaparecer la realidad y, simultáneamente, hacer desaparecer su desaparición.

Por mi parte quisiera referirme a algunas cuestiones esenciales de la seducción: su relación con el ser, con el erotismo y su registro estético, intentando, especialmente, confrontar la noción de seducción con las de producción y simulacro. Sobre el final, sugeriré que en Baudrillard se hallarían varias estéticas de la seducción. 


\section{El ser de la seducción}

La seducción, dice Baudrillard (2000), "nunca es del orden de la naturaleza, sino del artificio" (p. 9), es una ontología no metafísica; a decir de Holzapfel (2004), "un concepto filosófico fundamental, la filosofía misma está suscitada por la seducción”. Como bien dice Calomarde (1997), en Baudrillard, la seducción es "otro de los nombres del mundo, sólo que este nombre no daría razón de aquel, del mundo, sino razones de los artificios simulados que precipitarían la caída de su significado" (p. 152). Por su parte, Baudrillard afirma en Contraseñas: "La seducción a la que yo me refería es realmente el dominio simbólico de las formas" (Baudrillard, 2002, p. 32). De ahí que en el mismo texto señale que la seducción “es la esfera donde la intervención del ser es una especie de deontología” (p. 31).

Lo que el filósofo francés parece querer decir es que la incrustación del ser en la seducción es imposible salvo que, forzadamente, es decir, deontológicamente, este se imponga a partir de una axiología o de una ética, lo cual ya es producción (del deber ser por lo pronto) y deja de constituir una seducción.

Justamente, esta incrustación de la deontología en la seducción, esta dotación forzosa de sentido y, por tanto, pérdida del seducir, se define en términos de una ontología como prótesis, como artificialidad. La seducción “debe ser" algo únicamente para «todas las ortodoxias». La seducción de Baudrillard rechaza la figura del ser, pues la verdad y la realidad, la producción y el sentido, apuntan precisamente a esa indigencia ontológica de la cual la seducción es su forma desencantada.

Toda la angustia del vacío expuesta por la posmodernidad, todo ese horror vacui puesto en juego por el teatro actual del simulacro obligaría, derrumbada la ilusión salvaje del pensamiento, a cautelar la sobrevivencia de un último sistema de interpretación, el de una reproducción indefinida de los modelos. Para decirlo de otro modo, la seducción es la única posibilidad de ir más allá de la simulación.

Al respecto, Holzapfel verá la seducción como sucesivas aperturas del ser. Este es seducción: "seducir es ser seducido", aun cuando también pueda ser "re-seducido" o "des-seducido". 
Lo radical en todo caso, afirma el filósofo chileno, es que "el ser seduce donando sentido". Añade el autor de A la búsqueda del sentido:

Una de las claves de la teoría de la seducción de Baudrillard consiste en que la seducción actúa mediante la absorción de los sentidos de las cosas, es decir, sucede en ella que los signos que se ponen en juego literalmente se "tragan" los sentidos, por lo cual ellos quedan cargados de lo enigmático y mágico (Holzapfel, 2005, p. 188)

Desde luego, el autor se refiere acá a la seducción genuina y no a la fría o vulgar, distinción que es indispensable para entender la siguiente máxima del chileno: la seducción es de la no-seducción (Holzapfel, 2005, p. 193). En otras palabras, la seducción solo seduce cuando no nos damos cuenta de ella (su seducir es secreto), cuando no la creemos seducción: "Apenas la seducción es desenmascarada, nuestra producción toma resguardos frente a ella para defenderse" (Holzapfel, 2005, p. 193). Por otra parte, la seducción tampoco está del lado de la verdad ni del decir, no es epistémica ni doxástica, sino paradoxástica, está más cerca, por así decirlo, de la anécdota, del cuchicheo, del déjà $v u$. De este modo, se restablece no solo como otra realidad, sino, imperceptiblemente, como la más peligrosa, pues apareciendo a las sombras de la producción nos hace, «en un solo movimiento», quedar en sus manos y sucumbir.

Destaquemos la sugerente observación de Valiente (2012): “La seducción también funciona como agujero negro de toda verdad, de toda linealidad; está más allá del principio de realidad". Como radicalmente dice Baudrillard (2000): "Todo es seducción, sólo seducción” (p. 81). De tal manera que la seducción lo que confirma es la disolución de la dualidad sujeto-objeto como matriz irreversible de lo posmoderno; lo que está en juego en el seducir, como maniobra prioritaria, es justamente la reversibilidad, ese venir de vuelta de una producción des-seducida de sentido.

Resumiendo: la seducción resulta ser un embrujo, no una estrategia; un enigma, no un acertijo; una metafísica esotérica en vez de una ontología exotérica. Completa inactualización de toda demanda de producción, llámese esta verdad, poder, bien, sentido o placer. 
A propósito del desvío de estos sentidos que propicia la seducción, Holzapfel observa:

Desde la mirada de Baudrillard la seducción es pura y simplemente este desvío, que no tiene contemplaciones ni se rige en absoluto por la legitimación, justificación o sentido que pudiera tener. Justamente porque nos aparta de todo aquello, ella puede ir de la mano con lo que sería para nosotros una crueldad (Holzapfel, 2005, p. 169)

Aun cuando debamos reconocer la ausencia de un orden metodológico en su teoría, Baudrillard presentará la seducción como una figura que ha adquirido, como antes veíamos, distintos rostros en distintas épocas. Tres serían estas formas históricas de la seducción:

- La seducción como forma mágica y ceremonial, propia de las culturas arcaicas. (Fase ritual).

- La seducción como obra del diablo, a partir de la llegada del cristianismo. Se trata de la seducción pagana o perversa como juego maldito de las apariencias. (Fase estética).

- La seducción como desvío o curva de la producción en la era de la tecnicidad.

Es la seducción pura, distinta a la seducción del simulacro o de la cultura touch. (Fase política).

Podríamos decir que en la fase política (o sea en nuestros tiempos) vivimos inmersos, capturados por la seducción del simulacro, tanto así que la creemos la verdadera seducción. Veamos dos situaciones.

Tenemos, por un lado, las nuevas formas de terrorismo (lo que algunos han llamado terrorismo hipermoderno). Vemos hoy una manifiesta seducción como producción, por ejemplo, en la forma de reclutamiento de jóvenes con que opera el Estado Islámico en algunos países de Occidente. El caso de las jóvenes es a lo menos llamativo. Movidas por una maquinaria de seducción que les promete un lugar relevante en la construcción de un califato de corte medieval (están llamadas a ser las esposas y madres de la futura generación de yihadistas), las mujeres, muchas de ellas niñas, se embarcan en un proyecto complejo de descifrar, pero que tiene facetas utópicas, humanitarias, románticas y religiosas bastante evidentes. 
En este caso, se trata de un seducir como simulación, una especie de impronta cultural que ha normalizado (como dotación de sentido) la condición del mundo como radicalmente imperfecto, a propósito Baudrillard (como se citó en Vaskes, 2008) expresa: “el mundo sólo existe gracias a la ilusión que proviene de la imperfección radical, la que nos asegura la existencia del mundo accidental, criminal, violento, enfermo, en otras palabras - imperfecto (por eso, sólo nos puede ser dado como ilusión)". Este esnobismo maquinal que pareciera seducirnos llega a mostrarse detalladamente por Internet mediante acciones de ejecución (individuales o masivas) que nos dejan atónitos, paralizados, horrorizados.

Es el funcionamiento perfecto del principio de no realidad como "consecuencia de la expansión de la esfera tecno-electrónica-digital" (Vaskes, 2008, p. 204). Tal como se aprecia en la red, las ejecuciones son presentadas en formato prácticamente de cine, con detalles espeluznantes. Lo que nos seduce es el terror. Se trata, en ambos momentos, de una seducción psicologizada, de una simulación como telerrealidad. Como bien dice Vaskes (2008): "de la lógica hiperreal del montaje" (p. 206). Aun así, en el ejemplo aludido vemos cómo el feroz dominio integral del imaginario ejecutado por el Estado Islámico, sofoca, absorbe, anula la fuerza de imaginación singular de un Occidente atrapado en su propio simulacro de sensibilidad.

Por otro lado, en el mundo de la pintura, es frecuente que cuando tenemos la oportunidad de visitar una galería de arte nos desencantemos frente al cuadro real que antes habíamos visto en libros de pintura o en nuestro teléfono inteligente. El cuadro ante nosotros seguramente es más oscuro, menos brillante y más pequeño de lo que suponíamos. Pasa que estábamos seducidos por otros colores, otros pixeles y otros contrastes, por una estética de la edición, de la retroiluminación. Caímos, en este caso, en la seducción de la simulación, o para ser exactos, en el simulacro del Internet de las cosas. 


\section{El eros de la seducción}

Ante todo, la seducción hace reversible el erotismo. Dice Jean Baudrillard (2000): "En el fondo, la pura demanda sexual, el enunciado puro del sexo son imposibles. No se libera uno de la seducción, y el discurso anti-seducción es la última metamorfosis del discurso de seducción" (p. 46). Lo claro es que la seducción no es de naturaleza sexual, amorosa, porno o digital. Tampoco es flirteo, affaire o estrategia romántica (por ejemplo, una donjuanada no es seducción). La filosofía del deseo no puede, pues, seducir.

La cuestión es que en la seducción lo erótico anula la dualidad amor-sexo, o la de lo femenino-masculino, o incluso aquella de seductor y seducido. Se ve así que el Eros galante, el Eros sexual o el Eros pasión no son más que formas de la producción que encubrirían la transparente presentación del Eros de la seducción. Menos aún la seducción es publicidad, conquista o prostitución. Está más cerca, piensa Baudrillard (2000), del «travestismo»: "En ellos [travestis] todo es maquillaje, teatro, seducción" (p. 19), pues lo que seduce en este caso no es la atracción sino la «vacilación sexual». Y esto es así porque lo que hay detrás de este travestismo, en realidad, es la idea de performance, en el sentido radical de una acción performativa. Desde luego, esta noción de performance hace estallar la concepción moderna de subjetividad, "haciéndola entrar en diálogo con eso que el pensamiento contemporáneo ha llamado la alteridad” (Barría, 2011, p. 116).

La performance, entonces, representa el gasto sacrificial del sujeto performer y del sujeto espectador y lo que ejecuta es, precisamente, la desinteriorización del sujeto. Es decir, es un dispositivo tal que extasía a la subjetividad, a través y, sobre todo, de la disolución de las fronteras de las identidades asignadas a los individuos (Barría, 2011). En corto: seducción pura.

No deja de ser, pues, sugerente interpretar la performance como una forma de reflexión que cuestiona las políticas de la virtualidad, en especial, respecto a las políticas de la ficción que autoriza lo que puede ser objeto de ficción y qué no (Barría, 2011). 
La performance seduce justamente por el quiasmo o transgresión que plantea: “no dejar rastros", al modo de una negación a participar en el sistema de intercambio o reproducción (Phelan citado en Barría, 2011, p. 118). Tal como señala Peggy Phelan en La ontología de performance: representación sin reproducción (s.f.), el ser del performance se hace a sí mismo a través de su desaparición.

De cualquier manera, no debe escapársenos que la seducción sigue siendo femenina: ahí está su origen. Aunque subrayemos que en el filósofo lo femenino deja de ser lo que hasta ahora entendíamos por tal. En la seducción, lo femenino pasa a ser una "forma transversal de todo sexo, y de todo poder, como forma secreta y virulenta de la insexualidad" (Baudrillard, 2000, p. 22). En realidad, lo que hay es una transsexualidad de la seducción (Baudrillard, 2000).

Resumiendo: el erotismo de la seducción no es más que un juego banal: "me muestro esquivo, no me harás gozar, soy yo quien te hará jugar, y quien te hurtará el goce. Juego movedizo, donde es falso suponer que sólo es una estrategia sexual" (Baudrillard, 2000, p. 27). No obstante, al haber una «soberanía de la seducción», lo que vemos sobre todo es una especie de montaje destinado a posponer la satisfacción del deseo, vale decir, un ilusionismo, o siendo más precisos, un escapismo, en la medida en que todo escapista reaparece más tarde por donde menos se espera. En otras palabras, una virtual simulación.

\section{Estéticas de la seducción}

En la era postindustrial, es la seducción y no el simulacro la que vendría a expresar el sentido de una estética propiamente trascendente o discontinua, puesto que Baudrillard cree que lo que se expresa en el simulacro sería más bien una transestética, esto es, una estética que ha perdido su propia especificidad: una estética de la simulación.

Esto querría decir que la verdadera estética de la seducción consistiría, indistintamente, en varias estéticas dentro de posibilidades infinitas, pues la seducción se revelaría como una historia de incesto consigo misma, lo que nos lleva a recordar el canto seductor de las sirenas, el cual es visto por Barrera a modo de una estética del crimen. 
En su artículo La seducción como estética y en concordancia muy íntima con la propuesta de Baudrillard, la filósofa sugiere que si bien los autores que han interpretado la razón desmitificada han llegado hasta Ulises -el hombre que razonacomo el protagonista del lazo entre el mito, el trabajo y el dominio, lo que no se ha hecho, sin embargo, es considerar a "las sirenas como los protagonistas del lazo entre el mito, la seducción y la intuición" (Barrera, 2012, p. 20). Es decir, habría una preeminencia del mito y la seducción (de la seducción como mito o como muerte en la forma de canto de las sirenas) respecto de la llamada producción.

En torno a esto, el filósofo Paul Virilio nos propone una idea fascinante sobre la relación original entre estética y seducción, a propósito de lo que él llama "distanciamiento de la seducción":

Satanás, aparece en la Biblia como el seductor de la mujer, que, a su vez, seduce al hombre, dando así comienzo al ciclo de la Humanidad destinada no tanto a la muerte cuanto a la desaparición, es decir a la expulsión del universo en el que vivía, y esto se cumple en principio como fenómeno de la conciencia. En efecto, la expulsión física del Paraíso terrenal está precedida por un violento desarreglo de la visión, que modifica completamente las apariencias del mundo en que vive la pareja: sus ojos se abren, ven que están desnudos, cubren su desnudez y buscan la manera de disimular, de sustraerse a la mirada de Dios (...). De hecho, la seducción, ese conducir al distanciamiento del se ducere, toma aquí una dimensión cosmodinámica, la seducción es un rito de paso de un universo a otro, que implica una colosal partida general para toda la Humanidad (Virilio, 1998, p. 87)

De acuerdo con Virilio, este paso de un universo a otro provocará no solo una metamorfosis de la vista, sino también "un disimulo inmediato, un «camuflaje» prudente de los cuerpos" (1998, p. 89). Basándonos en esta observación, notamos que, en la compleja filosofía baudrillardiana, estética y seducción aparecen virtualmente confundidas, camufladas una con la otra. Tal estética, infinita, incestuosa o de la discontinuidad, pareciera mostrarse mediante los siguientes cuatro modos fundamentales (otros probablemente menores, serían también el vértigo, el mito, el adorno y el sortilegio, como formas predilectas de la seducción ritual). 


\section{La seducción como fantasma}

La seducción "sólo opera al ser un fantasma”, escribe Baudrillard. Esto en el sentido de que la seducción ha sido hasta ahora una mera inmaterialidad que ha venido jugando el juego del doble, de "un intercambio sutil de la muerte con el otro" (Baudrillard, 2000, p. 158). El filósofo galo entenderá esta dimensión fantasmática como una virtual «trampa de las apariencias»; lo opuesto a la materia muerta (el poder, lo virtual, el cálculo). Incluso, diríamos que la seducción tendría, a su vez, sus propios fantasmas que habitarían en el «espejismo ideal» de la producción y la realidad.

Estos espectros no serían otra cosa que el argumento de la sexualidad como modelo de simulación: «lo infinito del sexo», lo real absorbido en lo hiperreal, particularmente el porno, que pasará a ser desde ahora "la cuadrifonía del sexo", el "voyeurismo de la exactitud" (Baudrillard, 2000, p. 35). El porno elimina, desactiva toda seducción precisamente porque es el producto de un sistema de "disuasión de lo real por hiperrealidad" (Baudrillard, 2000, p. 39). La pregunta entonces es: ¿qué fantasma asedia al otro? ¿El porno y sus sustitutos hiperreales a la seducción, o al revés? Para ponerlo de otra forma: ¿quién es más fantasma? Al parecer, la violencia técnico-artificial del porno le teme a la seducción, en especial a su lógica espectral de escaparse de lo obsceno, del hard core y de no estar en ninguno de los orificios de sus muñecas sexuadas y, aun así, atraparnos y desviarnos: seducirnos.

El filósofo Derrida propone el neologismo fantología para indicar algo parecido a una ontología de lo fantasmal que pudiera asemejarse a este modo de ver la seducción. En cuanto a los fantasmas de Derrida, al igual que la seducción de Baudrillard, son espíritus por conjurar, seres pálidos sobre los que se tiene una pavorosa hostilidad. En Espectros de Marx, dice el filósofo de origen argelino:

Esa hostilidad hacia los fantasmas, una hostilidad aterrada que se defiende, a veces, del terror con una carcajada, es tal vez lo que Marx habrá tenido siempre en común con sus adversarios. Él también habrá querido conjurar los fantasmas, y todo lo que no fuera ni la vida ni la muerte, es decir, la reaparición de una aparición que nunca será ni el aparecer ni lo desaparecido, ni el fenómeno ni su contrario (Derrida, 1998, p. 61) 
De manera que el exorcismo del fantasma de la seducción sigue siendo preocupación incesante de la producción, o para decirlo bien, de la seducción del simulacro. No obstante, la forma blanca de la seducción difícilmente pueda ser exorcizada, porque, preguntamos con Derrida, “¿en qué se reconoce un fantasma? En que no se reconoce en un espejo" (Derrida, 1998, p. 175).

Krista Diehl, la protagonista de la novela Ave del Paraíso. De manera que el exorcismo del fantasma de la seducción sigue siendo preocupación incesante de la producción, o para decirlo bien, de la seducción del simulacro. No obstante, la forma blanca de la seducción difícilmente pueda ser exorcizada, porque, preguntamos con Derrida, "¿en qué se reconoce un fantasma? En que no se reconoce en un espejo" (Derrida, 1998, p. 175). de Joyce Carol Oates, hace una muy interesante reflexión sobre la posibilidad de ver los sueños como presencias omnipotentes:

¡La increíble autoridad de los sueños! Siempre me ha asombrado cómo nos rendimos a esas presencias nocturnas, tan confiados y vulnerables como si nos hubieran despojado de la capa más exterior de nuestra piel. En el sueño no hay protección, ningún sitio a donde ir, donde esconderse; no puede haber consuelo si el sueño mismo no es un consuelo (Oates, 2010, p. 205)

Podemos entender los sueños acá en distintos sentidos: como completa vulnerabilidad o como total desconsuelo. En todo caso, nos rendimos a ellos, dice el personaje. Somos seducidos. Lo mismo ocurre en el mito griego de Endimión y Selene, donde hallamos una íntima conexión entre sueño y seducción. De hecho y según el relato, la diosa solo podía, en principio, amar a Endimión mientras este dormía. Dormido él y la diosa despierta se amaron por mucho tiempo sin saber la fascinación que se profesaban el uno al otro. El mito concluye con la intervención de Zeus, quien a petición de Selene y como único modo de inmortalizar su amor, decide que Endimión no envejecería mientras estuviese dormido, único momento en que podría amarse con la diosa. La pintura ha reconocido la fascinación por esta historia en las obras, entre otros, de Sebastiano Ricci, Anne-Louis Girodet, de Roussy-Trioson y Edward John Poynter. 


\section{La seducción como ilusión}

Baudrillard nos hace caer en cuenta de que la seducción opera sistemáticamente en la forma de una metafísica radical del fingimiento. Como ahora veremos, recurre al arte, al mito y a la astrología para ejemplificar la eficacia de la ilusión como estrategia del seducir.

En primer lugar, en el mundo del arte nos hace presente la «inquietante extrañeza del trompe-l'oeil», de la pintura que nos engaña la vista, que se hace pasar por lo real. Con respecto a esto Baudrillard afirma: "En el trompe-l'oeil [más falso que lo falso] no se trata de confundirse con lo real, se trata de producir un simulacro con plena consciencia del juego y del artificio" (Baudrillard, 2000, p. 64). Los objetos del trompe-l'oeil (sin referencia, aislados, sacados de su marco) parodian la teatralidad de la vida, remedan la tercera dimensión, pero anacrónicamente, mediante un exceso de realidad. Por lo mismo, la seducción del trompe-l'oeil no es estética (el trompe-l'oeil ya no es pintura) sino metafísica: "proviene de una sorpresa radical de las apariencias” (Baudrillard, 2000, p. 65). La «hipersimulación experimental» del trompe-l'oeil no es arte sino alegoría, o lo que es igual, simulación pura.

En segundo lugar, en el capítulo I'll be your mirror, Baudrillard recurre al mito de Narciso para mostrarnos cómo la seducción podría entenderse mejor desde una suerte de teoría de la absorción y no desde una teoría del reflejo. Para el filósofo del simulacro, en la seducción está abolida la distancia entre identidad y alteridad, entre el mismo y el otro o entre el mismo y su reflejo o imagen de sí. La seducción de Narciso, sostiene Baudrillard, ocurre realmente cuando el joven "se pierde en su imagen ilusoria: se desvía de su propia verdad y con su ejemplo, se vuelve modelo de amor y aparta a los demás de la suya" (Baudrillard, 2000, p. 69). Sea lo que sea que Narciso se haya representado con su imagen en el agua, lo cierto es que llega a ser seducido (absorbido) por el aparecer/morir de una ilusión secretamente incestuosa (¿su reflejo es él mismo?, ¿su hermana gemela muerta, quizá?). Lo que le seduce a Narciso, concluye Baudrillard, es su propia imagen ante la inminencia de la muerte, como sacrilegio que rodea a todo incesto. Definición de seducción narcisista: una historia incestuosa disfrazada de ilusión. 
Seguidamente, el sociólogo-filósofo interpretará al Zodiaco, o sea, el destino visto como fuerza de los astros, como un engaño conveniente en razón del poder de seducción que la constelación de nuestro nacimiento tendría sobre nosotros. De nuevo el disfraz de la ilusión: "Todos buscamos la gracia de un destino insensato" (Baudrillard, 2000, p. 70). En otros términos, cada signo del horóscopo puede ser visto como predestinación: para bien, si somos seducidos por ellos, o para mal, si no lo somos.

\section{La seducción como muerte}

En la muerte, puntualmente en la figura del sacrificio, la seducción confirma ser, sin más, estética de la desaparición. Nótese que no se trata en la seducción de aquellas muertes propias del simulacro -el clon y la prótesis, por ejemplo-, sino de la muerte vista como destino. "El asombro de la muerte es lo encantador, el asombro de un arreglo tan frívolo, y que las cosas corran de esa manera al azar" (Baudrillard, 2000, p. 72). Mas esta muerte no se presentará como un destino objetivo, sino como una cita. Baudrillard escribe en el capítulo La muerte en Samarkande: "Ella misma [la muerte] no puede dejar de ir puesto que es esa cita, es decir, la conjunción alusiva de signos y de reglas que se acoplan" (2000, p. 72).

De acuerdo con lo anterior conviene tener en cuenta nuevamente a Holzapfel:

Más aún, la muerte no es únicamente "alguien" que sabe nada más lo que de su ser cita (si es que siquiera pudiera decirse, que sabe algo y no simplemente es), sino que su comportamiento es frívolo, incluso simpático, como el de una persona abierta y comunicativa -así se muestra ante el rey que la ha mandado llamar-, casi parece tratarse de una chiquilla locuela, ingenua que no sabe quién es, en qué está metida y ni siquiera cuál es propiamente su métier (Holzapfel, 2005, pp. 189 y ss.) 
Esta muerte inefable nos trae a la memoria el cuento de Franz Kafka, Ante la Ley, de 1914. En este relato, solo cuando el campesino que ha querido entrar a la ley (y cuyo paso ha sido durante años sistemática e inexplicablemente cerrado por el guardián) está próximo a morir, vale decir, cuando hace su aparición justamente la muerte como personaje decisivo, se le revela, en efecto, que aquella entrada estaba destinada solamente para él, o lo que es igual, que la puerta se cerrará, pues su muerte hace imposible que el juego de entrar/no entrar siga vigente («Ahora cerraré», sentencia el guardián en las últimas palabras del cuento). En el fondo, la ley kafkiana se revela como una forma sin sentido, inviolable, infranqueable, cuyo significado aproximado solo tiende a revelarse con la misma llegada de la muerte. Aparece la muerte y el acceso a la ley termina (la entrada se cierra). Pareciera que el único destino posible no era el acceso a la ley, ni el cambio de entrada, ni menos el de guardián, sino que la única regla posible era la muerte. Solo la muerte permite mostrar la verdad de la ley. La ley es la muerte.

Tiene sentido entonces para ambas muertes, la de Samarkande y la kafkiana, lo que afirma Baudrillard (2000): "Nada podría haberse dejado de cumplir y, sin embargo, todo conserva la ligereza del azar, del gesto furtivo, del encuentro accidental, del signo ilegible. Así funciona la seducción” (p. 72).

\section{La seducción como juego}

En el capítulo La pasión de la regla, el filósofo franco-argelino se refiere a la seducción simplemente como juego. Sin embargo, el juego de la seducción es un juego sin libertad: no obedece a la dialéctica del libre arbitrio. Ante todo, seduce porque es serio, nunca desenvuelto ni obsceno, y se funda no en el principio del placer sino en el del artificio (como vimos en la referencia al erotismo). Importa acá revisar la noción de azar que propone Baudrillard, pues en ningún caso se trata del azar entendido como buena o mala suerte: "El juego de azar niega cualquier distribución aleatoria del mundo" (Baudrillard, 2000, p. 136). 
Citemos en detalle al filósofo:

El azar en nuestro sentido de dispositivo aleatorio, de pura probabilidad sometida a la ley de probabilidades (y no a la regla del juego), ese azar moderno de concepción racional: especie de Gran Neutro Aleatorio (G. N. A.), resumen de un universo flotante dominado por la abstracción estadística, divinidad desdivinizada, desunida y desencantada - ese azar no existe en absoluto en la esfera del juego (Baudrillard, 2000, p. 135)

En la seducción lo que seduce es el azar como destino, o si se prefiere, el alea como designio, significado que vemos, por ejemplo, en la célebre frase atribuida a Julio César, alea iacta est («la suerte está echada» o «los dados están echados»), dicha, según varias fuentes, cuando el comandante ordena a su ejército, desafiando a la facción republicana del senado liderada por Pompeyo y rompiendo la legalidad romana, cruzar el Rubicón y avanzar rumbo a Roma, jugándoselo todo a una carta. La clasificación de los juegos que sugiere Roger Caillois en su obra de 1958, Los juegos y los hombres, particularmente en el caso de los juegos de alea, coincidiría del todo con la postura baudrillardiana.

\section{Escuchemos a Cristóbal Holzapfel:}

En cuanto a los juegos de alea, durante milenios éstos fueron vivenciados como juegos de destino. Tengamos en cuenta al atleta griego, para el cual el juego o deporte que practica está ligado a la voluntad divina. Lo que ocurre con la competencia en la que se encuentra es decidido en una instancia nohumana. Ello nos muestra a la vez la relevancia del juego de alea como juego de destino, por cuanto el agon es asumido durante milenios siempre como alea del agon; en otras palabras, no solo tus dotes, talentos, destrezas y habilidades agonales te han sido dadas, sino que lo que hagas con ellas se decide en otra parte. Mas, en la modernidad sucede que el alea comienza a ser manipulado, convirtiéndose estos juegos en juegos de lo meramente aleatorio, de azar (Holzapfel, 2011, p. 208) 
El juego de la seducción, por lo mismo, es el juego de azar y no el juego de alea (a menos que hablemos en sentido cailloisiano). El azar seducido por el azar, el juego como "intento de seducción del azar" (Baudrillard, 2000, p. 136). Suponer, plantea Baudrillard, una hipótesis que sugiera la ocurrencia aleatoria, por ínfima que sea la probabilidad de que las series más distantes de algo, por ejemplo, dos cifras o dos cadenas, se crucen en algún momento; eso precisamente, desprovisto de toda regla, es el evidente desorden objetivo, el azar objetivo de la realidad, no el del juego sino el del alea. El vértigo ideal, el de la seducción, es el del «azar atascado», "el de la jugada de dados que acaba por «abolir el azar», cuando, contra toda probabilidad, el cero sale varias veces seguidas" (Baudrillard, 2000, p. 139).

Para ilustrar esta idea, Baudrillard trae a colación el cuento de Borges, La lotería en Babilonia (1941), donde el juego de azar se impone finalmente como lo esencial en el orden social de esta sociedad ficticia. ¿O acaso no nos seduciría el participar gratuitamente en un juego secreto y sagrado, que de un día para otro a uno lo convierta en hombre rico, o un mago, o hacerle obtener la mujer que desee, o lo destine a la mutilación... o a la muerte? Se trata, al fin y al cabo, de la completa indiferencia "entre lo real real y lo real aleatorio" (Baudrillard, 2000, p. 142). Más aún: nunca sabremos si la fortuna o infortuna del sorteo es producto de un presunto movimiento de esta sociedad secreta que administra el sorteo o meramente fruto del azar total.

Baudrillard completará su teoría del juego en el capítulo Lo lúdico y la seducción fría. El filósofo se empeña acá en desmarcarse de lo lúdico, al que entenderá como aquel universo "donde todo adquiere efecto de simulación posible" (Baudrillard, 2000); esto es, donde hay un modelo o respuestas simuladas respecto de un deseo o demanda de tales respuestas. Lo lúdico es eso: una solicitación resuelta por medio del principio del placer, "el encanto «narcisista» de los sistemas electrónicos e informáticos" (Baudrillard, 2000, p. 153). Obviamente, lo que quiere decir Baudrillard es que lo lúdico es el juego de la producción. En efecto, la producción ha expurgado al juego de su fuerza propia de seducción, lo ha degradado a rango de mera función. A este fin da una serie de ejemplos que representan hoy en día lo lúdico: la solicitación publicitaria, el juego-terapia, la TV por cable con su mezcolanza de canales y programas, los juegos electrónicos. 
Como contrapartida, Baudrillard pone como ejemplo de un juego no lúdico al ajedrez. Efectivamente, solo el ajedrez parece mantener el desafío y la pasión de la ilusión. En el ajedrez el juego se expresa esencialmente como una relación dual y agonística, ajeno a toda posibilidad de convertirse en un sistema de juego o modulación cibernética (salvo que juguemos contra un ordenador). De tal manera que a la seducción no solo conciernen, siguiendo a Caillois, los juegos de azar, como antes veíamos a propósito de La lotería en Babilonia. También esta clase de juego de agon, como el ajedrez, absorbe lo esencial de la seducción, al verse los contendores frente a frente obligados a desempeñar/jugar un ritual puramente agonístico (aunque el juego parta en forma aleatoria con la elección de los colores de las piezas). Es más, la misma jugada decisiva, la final, habla de manera clara acerca de que lo que está en juego es la competencia: ¡Jaque mate! (¡El rey no tiene escapatoria!). Es, pues, en el ajedrez donde vemos sobre todo la expresión de la regla.

Volvamos a Holzapfel, ahora en su Crítica de la razón lúdica:

La regla a la que se someten los juegos y los rituales sólo tiene un sentido inmanente (que es completamente arbitrario, como que en ajedrez el caballo se mueva como se mueve, o en un ritual haya que danzar alrededor del fuego) (Holzapfel, 2003, p. 103)

Sin embargo, es más fascinante considerar el destino como cosa determinante respecto del propio juego. Por más cálculos que haga sobre las probabilidades de movimiento de las siguientes jugadas de mi adversario, es innegable que el juego puede irse por otro lado: puedo perder con un jaque mate, pastor que no vi venir o producto de una defensa india, siciliana o escandinava de mi contendor que, sorpresivamente, transformó su jugada en un ataque mortal, o me distraje y no aproveché la oportunidad de "comerme" una pieza decisiva. Hay algo más allá como determinación del juego, que se revela en el límite del vértigo. Bajo este mismo orden de ideas agrega Holzapfel: 
La pasión, el hechizo del ajedrez están sin duda en seguir los vericuetos de una lógica implacable, en adelantarse a la secuencia absolutamente lógica de los movimientos que tendrían que conducir al jaque mate. Pues bien, como en esa aventura, en esa anticipación de la secuencia secreta de algo que no es al fin y al cabo otra cosa que una figura de un determinismo lógicomatemático, justamente en vistas del descubrimiento de ese orden secreto, lo que es determinismo lo vivenciamos como destino (Holzapfel, 2003, pp. 110 y ss.)

\section{Conclusiones}

Intentar sugerir una filosofía de la seducción en Baudrillard se ha mostrado como un riesgo proposicional de marca mayor. Justamente, debido a ese estado de interdicción semántica, lógica y metafísica que hace imposible su intercambio con el ser.

Del lado de la ausencia completa de sentido, la seducción esquiva la confrontación agonal entre realidad y simulacro, ubicándose radicalmente en el plano de la no representación. Podría pues perfectamente decirse, con Francescutti, que es más probable hallarla en los lindes de la ciencia ficción. En verdad, la seducción viene a ser un último sistema de interpretación.

A partir de esta imposibilidad de traducción ontológica y productiva, la seducción da el golpe de gracia, eludiendo incluso su registro estético y ofreciendo un fondo erótico perturbadoramente ambivalente. De modo que, lo que de veras expone sus fases ritual, estética y política, es una invariable condición de reversibilidad de una producción des-seducida de sentido, en la forma de magia, paganismo y desvío.

Estéticamente, parece absorber una discontinuidad que finalmente revela un erotismo más cercano al rendimiento de la performance, especialmente, por su estratagema de "no dejar rastros", en la forma de una contra-política de la virtualidad. Se trataría, indistintamente, de varias estéticas de la seducción dentro de posibilidades infinitas, en una idea bastante más parecida a la de series de sentido que hallamos en Deleuze. 
Tal estética, infinita, incestuosa y paradójica, adquiere, a su vez, su mejor performance en los modos fundamentales de la ilusión, el fantasma, la muerte y el juego, aun cuando también serían otras formas de la seducción el vértigo, el mito, el adorno y el sortilegio.

Sin embargo, lo esencial es otra cosa: la constatación de la imposibilidad de concluir discursivamente sobre la seducción, puesto que parece ser ella misma la fuente de todo último sentido.

En plena era de la «inmanencia cool», la seducción «blanda» como postestética del Internet, busca dar por perdido cualquier rastro de seducción heterodoxa. Pero, el maleficio sobrevive. A fin de cuentas, la seducción no es más que un juego de velos. En realidad, como en el célebre certamen de Zeuxis y Parrasios, solo una diabólica simulación de la simulación.

\section{Referencias}

Barría, M. (2011). Performance y políticas del acontecimiento. Una crítica a la noción de espectacularidad. Aletria, 21(1), 111-119. Recuperado de https://tinyurl.com/y5sa88xm

Barrera, C. (2012). La seducción como estética. Calle 14 Revista De Investigación En El Campo Del Arte, 6(8), 8-15. Recuperado de https:// tinyurl.com/yyxyspag

Baudrillard, J. (2000). De la seducción. Madrid: Cátedra.

Baudrillard, J. (2002). Contraseñas. Barcelona: Anagrama.

Calomarde, J. (1997). Los objetos penúltimos. Madrid: Huerga y Fierro.

Derrida, J. (1998). Espectros de Marx. Madrid: Trotta.

Francescutti, L. P. (2011). Baudrillard, una sociología de ciencia ficción. Espéculo: Revista de Estudios Literarios (47). Recuperado de https:// tinyurl.com/y4uom $25 \mathrm{q}$ 
Holzapfel, C. (2003). Crítica de la razón lúdica. Madrid: Trotta.

Holzapfel, C. (2004). Seminario Aproximaciones filosóficas al erotismo [Material de aula]. Doctorado en Filosofía, mención Estética y Teoría del Arte, Universidad de Chile, Santiago.

Holzapfel, C. (2005). A la búsqueda del sentido. Santiago: Sudamericana.

Holzapfel, C. (2011). Fenómenos existenciales fundamentales de Eugen Fink: juego y muerte. Revista de Filosofia, 67. Recuperado de https://tinyurl. com/y6xww4dq

Oates, J. C. (2010). Ave del paraíso. Santiago: Alfaguara.

Phelan, P. (s.f.). La ontología de performance: representación sin reproducción. [Registro web]. Recuperado de https://tinyurl.com/y2w5ctr6

Valiente, E. (2012, octubre 07). Pensarlo todo. Baudrillard, Jean. [Registro web]. Recuperado de https://tinyurl.com/yxg8cdck

Vaskes, I. (2008). La transestética de Baudrillard: simulacro y arte en la época de simulación total. Estudios de Filosofía, (38), 197-219. Recuperado de https://tinyurl.com/y4qn8qn3

Virilio, P. (1998). Estética de la desaparición. Barcelona: Anagrama. 